\title{
Effect of routine iron supplementation with or without folic acid on anemia during pregnancy
}

\author{
Mohammad Yawar Yakoob, Zulfiqar A Bhutta*
}

\begin{abstract}
Introduction: Iron deficiency is the most prevalent nutrient deficiency in the world, particularly during pregnancy. According to the literature, anemia, particularly severe anemia, is associated with increased risk of maternal mortality. It also puts mothers at risk of multiple perinatal complications. Numerous studies in the past have evaluated the impact of supplementation with iron and iron-folate but data regarding the efficacy and quality of evidence of these interventions are lacking. This article aims to address the impact of iron with and without folate supplementation on maternal anemia and provides outcome specific quality according to the Child Health Epidemiology Reference Group (CHERG) guidelines.
\end{abstract}

Methods: We conducted a systematic review of published randomized and quasi-randomized trials on PubMed and the Cochrane Library as per the CHERG guidelines. The studies selected employed daily supplementation of iron with or without folate compared with no intervention/placebo, and also compared intermittent supplementation with the daily regimen. The studies were abstracted and graded according to study design, limitations, intervention specifics and outcome effects. CHERG rules were then applied to evaluate the impact of these interventions on iron deficiency anemia during pregnancy. Recommendations were made for the Lives Saved Tool (LiST).

Results: After screening 3550 titles, 31 studies were selected for assessment using CHERG criteria. Daily iron supplementation resulted in $73 \%$ reduction in the incidence of anemia at term ( $R R=0.27 ; 95 \% \mathrm{Cl}: 0.17-0.42$; random effects model) and $67 \%$ reduction in iron deficiency anemia at term ( $R R=0.33 ; 95 \%$ Cl: $0.16-0.69$; random model) compared to no intervention/placebo. For this intervention, both these outcomes were graded as 'moderate' quality evidence. Daily supplementation with iron-folate was associated with $73 \%$ reduction in anemia at term ( $R R=0.27 ; 95 \% \mathrm{Cl}: 0.12-0.56$; random model) with a quality grade of 'moderate'. The effect of the same intervention on iron deficiency anemia was non-significant ( $R R=0.43 ; 95 \% \mathrm{Cl}: 0.17-1.09$; random model) and was graded as 'low' quality evidence. There was no difference in rates of anemia at term with intermittent iron-folate vs. daily iron-folate supplementation ( $\mathrm{RR}=1.61 ; 95 \% \mathrm{Cl}$ : $0.82-3.14$; random model).

Conclusion: Applying the CHERG rules, we recommend a $73 \%$ reduction in anemia at term with daily iron (alone) supplementation or iron/folate (combined) vs. no intervention or placebo; for inclusion in the LiST model. Given the paucity of studies of intermittent iron or iron-folate supplementation, especially in developing countries, we recommend further evaluation of this intervention in comparison with daily supplementation regimen.

\section{Introduction}

Around 2 billion people, amounting to over $30 \%$ of the world's population are anemic, mainly due to iron deficiency [1]. Iron deficiency is the most prevalent and also the most neglected nutrient deficiency in the world, particularly among pregnant women and children, especially in developing countries [2]. It is also significantly

\footnotetext{
* Correspondence: zulfiqar.bhutta@aku.edu

Division of Women \& Child Health, The Aga Khan University, Karachi,
} Pakistan prevalent in industrialized countries. Estimates say that globally, fifty six million pregnant women $(41.8 \%$ of the total) are affected with anemia, again mostly due to iron deficiency [3]. In developing countries, this proportion can be as high as $80 \%$ like in South Asia [4], making pregnant mothers susceptible to increased risk of mortality and decreased work capacity. It may also lead to other perinatal complications like pre-eclampsia, low birth weight, prematurity and perinatal mortality [5]. It is the poorest, most vulnerable and least educated who

\section{Biomed Central}


are disproportionately affected by iron deficiency, and it is this group that stands to gain the most by its reduction.

Anemia, as defined by low hemoglobin or hematocrit, is commonly used to assess the severity of iron deficiency in populations without high rates of malaria. The high physiological requirement for iron in pregnancy is difficult to meet with most diets. Therefore, pregnant women should routinely receive iron supplementation, especially in developing countries. Prenatal iron supplementation is not compulsory in many industrialized countries and the recommended dose is usually small (30 $\mathrm{mg}$ ferrous iron daily) [6]. However, for developing countries, the recommendation is a daily dose of $60 \mathrm{mg}$ of iron for pregnant, non-anemic women for six months and an increased dose of $120 \mathrm{mg}$ of iron daily if the duration of supplementation is shorter, if iron deficiency prevalence in women of a given country is high, and if pregnant women are anemic. This supplement should include $400 \mu \mathrm{g}$ of folic acid or lower doses if this amount is not available [7].

Earlier studies have provided sufficient evidence to show that iron supplementation with or without folic acid results in a significant reduction in the incidence of anemia during pregnancy $[2,8]$. There has also been a limited impact of iron supplementation in community settings owing to lack of compliance and poor infrastructure [9]. However, data regarding quality of evidence for the effectiveness of iron during pregnancy are lacking. Besides, the data on studies in developing countries have not been presented separately. This article is one of the series of papers that aim to determine efficacy of interventions for recommendations into the Lives Saved Tool (LiST), especially in developing countries and is, therefore, different from previously published systematic reviews. In LiST, increases in coverage of an intervention results in a reduction of risk factor or one or more causes of mortality. In this review, the recommendations are made based on application of adapted Grading of Recommendations, Assessment, Development and Evaluation (GRADE) approach for the quality of evidence and use of the Child Health Epidemiology Reference Group (CHERG) rules. For more details of the review methods, the adapted GRADE approach or the LiST model, see the methods paper for by CHERG group [10].

\section{Methods}

\section{Searching}

We systematically reviewed all published literature up to June 21, 2010 to identify studies of iron supplementation with or without folic acid during pregnancy on maternal anemia. As per the Child Health Epidemiology Reference Group (CHERG) systematic review guidelines
[10], we searched PubMed and the Cochrane Library, and included publications in any language available in these databases. Every effort was made to gather unpublished data when reports were available for full abstraction. Previous reviews on the topic were also handsearched to look for relevant studies $[2,8,11]$. We used the Medical Subject Heading Terms $(\mathrm{MeSH})$ and free text terms for the search strategy using a combination of terms for iron, folic acid and pregnancy, as follows:

("Iron"[Mesh OR "Folic Acid"[Mesh] OR iron OR folic acid OR folate) AND ("Anemia"[Mesh] OR "Anemia, Iron-Deficiency"[Mesh] OR anemia) AND (pregnancy OR maternal)

\section{Inclusion/exclusion criteria}

We limited our search to randomized and quasi-randomized trials conducted in both developed and developing countries, comparing the effects of preventive prenatal oral iron or iron + folic acid supplements among pregnant women versus no treatment/placebo. The developing countries were defined as countries with Gross National Income per capita (GNI) below US $\$ 11,905$, according to World Bank [12]. Pregnant mothers could be of any age or parity. Studies were included if iron or iron-folate was given alone to the intervention group. Those studies were excluded that assessed the effects of multiple combinations of vitamins and minerals except even if iron/iron-folate was the only difference among the study groups (arms). All included studies contained a placebo or a suitable control group that did not contain iron or iron-folate. There were no limits on gestational age at the time of enrolment in the study and the duration of supplementation. Studies of peri-conceptional or postpartum iron/ iron-folate supplementation were excluded. Studies of fortification of iron/iron-folate in food or studies in which iron was given in forms other than oral supplements like powder were excluded. Similarly, studies where iron or iron-folate was given in any parenteral formulation were excluded. Other exclusion criteria included trials of supplementation with multiple micronutrients (MMN) containing iron or iron + folic acid in comparison to supplementation with iron or iron + folic acid alone as this has been reviewed in another paper of this series [13]. Studies where iron/iron-folate was given to anemic pregnant women as a medical treatment were also excluded as the primary objective of this review was to assess the efficacy of preventive iron/folate supplementation for anemia during pregnancy. The therapeutic role of iron for anemia during pregnancy had been reviewed elsewhere [14]. We conducted sub-group analyses with respect to study country setting i.e. developed or developing. However, we did not specifically evaluate minor adverse effects of the supplements such as 
nausea, vomiting, headache or constipation among the pregnant mothers.

\section{Abstraction, analyses and summary measures}

Studies were included if data from one of the following outcomes was provided: anemia at term, iron deficiency anemia at term, severe anemia at term and severe anemia at any time during the second and third trimester. All outcome measures to be included were determined a priori. The interventions described in this review can be subdivided into four categories: 1) daily iron supplementation alone compared to placebo/control, 2) weekly iron supplementation alone compared to daily regimen, 3) daily supplementation of iron and folic acid versus placebo/control and 4) weekly supplementation of iron and folic acid versus daily supplementation.

All studies that met final inclusion and exclusion criteria were double-data abstracted into a standardized form for each outcome of interest. We abstracted key variables with regard to the study identifiers and context, study design and limitations, intervention specifics, and outcome effects. Each study was assessed and graded according to the CHERG adaptation of the GRADE technique [15]. Studies received an initial score of high if they were RCTs or cluster-RCTs (cRCTs). The grade was decreased by $0.5-1$ point for each study design limitation like inadequate methods of sequence generation, allocation concealment and attrition $>20 \%$ etc. In addition, studies reporting an intent-to-treat analysis or with statistically significant strong levels of association ( $>80 \%$ reduction) received $0.5-1.0$ grade increase. Any study with a final grade of very low was excluded on the basis of inadequate study quality.

For any outcome with more than one study, we conducted a meta-analysis and reported the Mantel-Haenszel pooled relative risk and corresponding 95\% confidence interval $(\mathrm{CI})$. In case of heterogeneity $(\mathrm{P}<$ 0.1 and $\mathrm{I}^{2}>50 \%$ ), the random effect model (DerSimonian-Laird) pooled relative risk and corresponding 95\% CI was used, especially where there was unexplained heterogeneity such as major differences in study design [10]. All analyses were conducted using RevMan 5 statistical software.

We summarized the evidence based on outcome by including assessment of the study quality and quantitative measures according to standard guidelines [10] for each outcome. For the outcomes of interest, namely the effect of iron/iron-folate on maternal anemia, we applied the CHERG Rules for Evidence Review [10] to recommend final estimates for reduction in anemia with iron or iron-folate supplementation. Additional file 1 contains a list of studies from the search that were excluded from the meta-analyses with a brief explanation for why the study was excluded.

\section{Definitions}

Anemia was defined as hemoglobin $(\mathrm{Hb})$ level of less than $110 \mathrm{~g} / \mathrm{L}$ and severe anemia was defined as hemoglobin level of less than $70 \mathrm{~g} / \mathrm{L}$. Iron deficiency anemia was defined as $\mathrm{Hb}$ less than $110 \mathrm{~g} / \mathrm{L}$ and at least one additional laboratory indicator (mean cell volume, haemoglobin concentration, serum ferritin, erythrocyte protoporphyrin concentrations etc) of iron deficiency .

\section{Results}

The search generated 3550 hits on PubMed and 290 in Cochrane Library that were screened and after removing duplicates, 81 abstracts were preliminarily selected. These were reviewed in detail, including full texts and finally 31 [16-47] studies were selected for inclusion in this paper. A detailed account of the number of abstracts and titles scanned is given as a flow chart (Figure 1). Table 1 gives the summary of the quality of evidence and the impact estimates of different interventions.

\section{Anemia at term}

This outcome was reported by 18 studies [16,17,19-21, 23,24,27,29,30,32-34,37-39,41,47]. Daily supplementation with iron only versus no intervention/placebo was evaluated by 14 studies $[17,19,21,23,24,27,29,30,33$, $34,37-39,41]$. There was a statistically significant $73 \%$ reduction in the incidence of anemia at term $(R R=$ 0.27; 95\% CI: 0.17 - 0.42; random model) (Figure 2). There were three studies $[16,17,21]$ that evaluated daily supplementation with iron and folic acid both versus no intervention/placebo and pooled data also showed a significant $73 \%$ reduction in anemia at term $(R R=$ 0.27; 95\% CI: 0.12 - 0.56; random model) (Figure 3). There was, however, no difference between intermittent iron-folic acid supplementation vs. daily ironfolate on this outcome based on three studies $[20,32,47](R R=1.61 ; 95 \%$ CI: $0.82-3.14$; random model) (Figure 4).

\section{Iron deficiency anemia at term}

This outcome was reported by seven studies $[23,27,31,33,34,43,45]$. Daily supplementation with iron alone versus no intervention/placebo had a significant $67 \%$ reduction in incidence of iron deficiency anemia at term based on six studies $[23,27,33,34,43,45](R R=0.33$; 95\% CI: 0.16 - 0.69; random model). There was one study [31] on daily iron-folic acid versus no intervention/placebo and the effect was large but non-significant $(\mathrm{RR}=0.43 ; 95 \%$ CI: $0.17-1.09 ;$ random model $)$

\section{Severe anemia at term}

This outcome was estimated by 13 studies $[16,18,20,23,27,30-35,41,45]$. Daily iron supplementation 


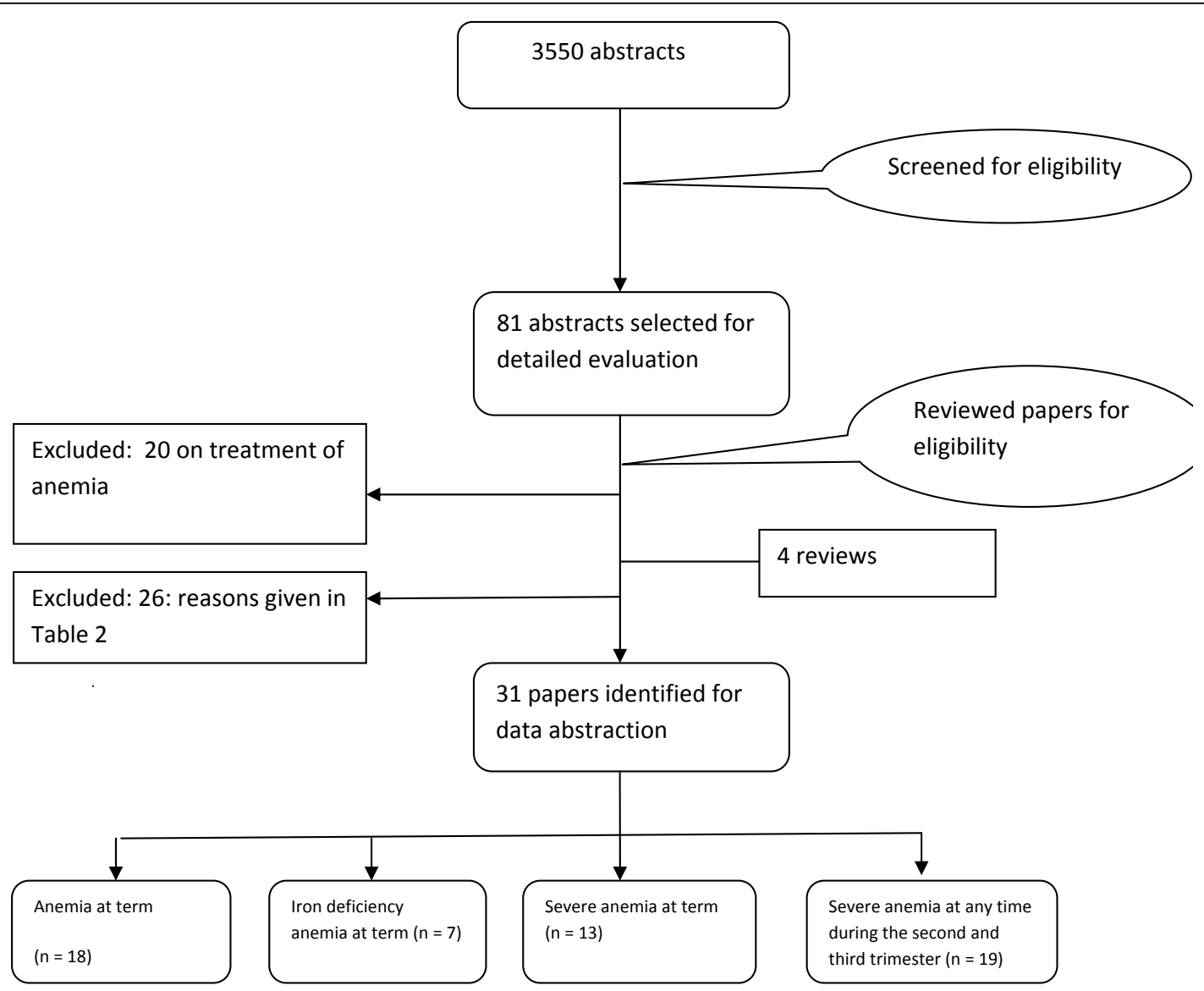

Figure 1 Flow chart of the literature search.

versus no intervention/placebo, as seen in 8 studies $[18,23,27,30,33,34,41,45]$, had a non significant adverse impact on severe anemia at term $(\mathrm{RR}=4.83 ; 95 \% \mathrm{CI}$ : 0.23 - 99.88; random model). This result was primarily based on one study [33] as all the other studies had zero events in both groups. Three studies evaluated the impact of daily supplementation with iron and folate both on severe anemia at term $[16,18,31]$, but the number of events in these studies in both groups was nil. Intermittent supplementation with iron and folate vs. daily supplementation of same micronutrients also yielded no severely anemic patients in the intervention and control groups in the three studies that looked at this outcome $[20,32,35]$.

\section{Severe anemia at any time during second and third trimester}

Severe anemia during second and third trimester was reported by 19 studies [16,18,22,23,25,27,28,30$32,36,40,42,44-46]$. Daily iron alone compared to no supplementation had no impact on severe anemia in second and third trimester based on nine studies [18,22,23,27,28,30,33,34,45], $(\mathrm{RR}=0.48 ; 95 \% \mathrm{CI}: 0.01-$
34.52; random model), with only two studies [22,33] having events greater than zero in the intervention and control groups. For intermittent iron alone vs. daily iron alone, there were two studies $[36,44]$ that looked at this outcome and both had zero events in the two groups. Daily iron-folic acid versus no intervention/placebo also had no effect on severe anemia at any time during second and third trimester based on four studies $[16,18,22,31](R R=0.11 ; 95 \%$ CI: $0.01-0.83)$, with zero events in three of these studies in both groups, except one [22]. Intermittent iron-folate vs. daily iron-folate outcome included 6 studies $[25,32,35,40,42,46]$ and events were nil in both groups in all these six studies.

\section{Discussion}

Iron supplementation alone or in combination with folic acid has been associated with the well being of the mother and fetus. It leads to a significant reduction in anemia incidence during pregnancy and, thus, plays a vital role in reducing maternal morbidity and mortality. The results of our review were consistent with those of an earlier Cochrane review by Pena Rosas and Viteri [2] that also showed a significant reduction in incidence of 
Table 1 Quality assessment of trials of iron and/or folate on the incidence of anemia during pregnancy

\begin{tabular}{|c|c|c|c|c|c|c|c|c|}
\hline \multirow{3}{*}{$\begin{array}{l}\text { No of } \\
\text { studies } \\
\text { (ref) }\end{array}$} & \multirow{3}{*}{ Design } & \multicolumn{4}{|c|}{ Quality Assessment } & \multicolumn{3}{|c|}{ Summary of Findings } \\
\hline & & \multirow[t]{2}{*}{ Limitations } & \multirow[t]{2}{*}{ Consistency } & \multicolumn{2}{|c|}{ Directness } & \multicolumn{2}{|c|}{ No of events } & \multirow[b]{2}{*}{$\begin{array}{l}\text { Relative } \\
\text { Risk } \\
\text { (95\% Cl) }\end{array}$} \\
\hline & & & & $\begin{array}{l}\text { Generalizability to } \\
\text { population of } \\
\text { interest }\end{array}$ & $\begin{array}{l}\text { Generalizability } \\
\text { to intervention } \\
\text { of interest }\end{array}$ & Intervention & Control & \\
\hline \multicolumn{9}{|c|}{ Daily iron versus no intervention/placebo Anemia at term: Moderate outcome specific quality } \\
\hline 14 & $\begin{array}{l}\text { RCT/ } \\
\text { quasi } \\
\text { RCT }\end{array}$ & $\begin{array}{l}\text { Studies with unclear or } \\
\text { inadequate sequence } \\
\text { generation and high loss } \\
\text { to follow-up }\end{array}$ & $\begin{array}{l}\text { All studies show } \\
\text { direction of benefit, } \\
\text { but high } \\
\text { heterogeneity }\end{array}$ & $\begin{array}{l}\text { Only two studies in } \\
\text { developing } \\
\text { countries, rest in } \\
\text { developed nations }\end{array}$ & Yes & 114 & 313 & $\begin{array}{c}\text { RR } \\
\text { (random) } \\
=0.27[ \\
0.17,0.42 \\
]\end{array}$ \\
\hline \multicolumn{9}{|c|}{ Daily iron versus no intervention/placebo: Iron deficiency anemia at term: Moderate outcome specific quality } \\
\hline 6 & $\begin{array}{l}\text { RCT/ } \\
\text { quasi } \\
\text { RCT }\end{array}$ & $\begin{array}{l}\text { Studies with unclear or } \\
\text { inadequate sequence } \\
\text { generation and high loss } \\
\text { to follow-up }\end{array}$ & $\begin{array}{l}\text { All studies show } \\
\text { direction of benefit, } \\
\text { with borderline } \\
\text { heterogeneity }\end{array}$ & $\begin{array}{l}\text { Only one study in } \\
\text { developing country, } \\
\text { rest in developed }\end{array}$ & Yes & 25 & 68 & $\begin{array}{c}\text { RR } \\
\text { (random) } \\
=0.33[ \\
0.16,0.69 \\
]\end{array}$ \\
\hline \multicolumn{9}{|c|}{ Daily iron and folic acid versus no intervention/placebo: Anemia at term: Moderate outcome specific quality } \\
\hline 3 & $\begin{array}{l}\text { RCT/ } \\
\text { quasi- } \\
\text { RCTs }\end{array}$ & $\begin{array}{c}\text { High loss to follow-up } \\
\text { and unclear sequence } \\
\text { generation }\end{array}$ & $\begin{array}{l}\text { Two studies show } \\
\text { direction of benefit; } \\
\text { while the third study } \\
\text { had zero events }\end{array}$ & $\begin{array}{l}\text { Only one study in } \\
\text { developing country, } \\
\text { rest in developed }\end{array}$ & Yes & 17 & 49 & $\begin{array}{c}\mathrm{RR} \\
\text { (random) } \\
=0.27[ \\
0.12,0.56 \\
\quad]\end{array}$ \\
\hline \multicolumn{9}{|c|}{ Daily iron and folic acid versus no intervention/placebo: Iron deficiency anemia at term: Low outcome specific quality } \\
\hline 1 & $\mathrm{RCT}$ & $\begin{array}{l}\text { Allocation concealment } \\
\text { unclear and blinding } \\
\text { inadequate }\end{array}$ & One study only & $\begin{array}{l}\text { In a developed } \\
\text { country }\end{array}$ & Yes & 12 & 5 & $\begin{array}{c}\mathrm{RR} \\
\text { (random) } \\
=0.43 \\
{[0.17} \\
1.09]\end{array}$ \\
\hline
\end{tabular}

anemia and iron deficiency anemia at term with daily iron supplementation and that of anemia at term due to daily iron-folate supplementation versus no intervention/placebo.

The pooled analysis of effect of daily iron supplementation vs. control had a high heterogeneity (fig 2). The most likely explanation of this substantial statistical heterogeneity $\left(\mathrm{I}^{2}=73 \%\right)$ is the variable effect size of the studies which in turn depend on the baseline anemia status of the study population. An important observation to make is that the direction effect in all the studies was in the same direction. We can expect that biologic effect of iron supplementation would differ based on prevalence of anemia in the study population. To further elaborate on this observation, we conducted a post hoc subgroup analysis based on baseline anemia status of the study population (data not shown). There were seven studies that included only non-anemic pregnant women based on laboratory evidence of absence of anemia (hemoglobin < $110 \mathrm{~g} / \mathrm{L}$ ) $[21,23,24,27,29,33,39]$ and in other seven studies, population was that of mixed status $[17,19,30,34,37,38,41]$. Pooled estimates for non-anemic women were less heterogeneous $\left(\mathrm{I}^{2}=47 \%\right)$ and size of summary estimate was less prominent (RR 0.31, $95 \%$
CI 0.19-0.52) compared to that of mixed population that had more heterogeneous $\left(\mathrm{I}^{2}=83 \%\right)$ and more prominent results (RR 0.22, $95 \%$ CI 0.11-0.47). This shows a strong biologic effect in favor of the intervention and also indicates that effect of Iron supplementation would depend on degree of baseline anemia in the study population.

CHERG rules were applied to the collective outcomes of anemia for recommendation of iron deficiency anemia into the LiST model. Daily supplementation with iron led to $73 \%$ reduction in incidence of anemia at term as compared to no supplementation. This intervention had a 'moderate' quality evidence owing to some limitations in included studies like unclear $[17,21,24,30,34,38,39,41]$ or inadequate sequence generation [19], and high loss to follow up [17,23,27]. Another limitation was that all the studies in the pooled analysis were not conducted in developing countries. In any case, based on strong biologic plausibility and consistent direction of effect across the studies, we recommend a $73 \%$ reduction in anemia at term with iron supplementation during pregnancy, for inclusion in the LiST model. Daily supplementation with iron and folate led to $73 \%$ reduction in incidence of anemia at term when 


\begin{tabular}{|c|c|c|c|c|c|c|c|c|c|}
\hline \multirow[b]{2}{*}{ Study or Subgroup } & \multicolumn{2}{|c|}{ Experimental (daily) } & \multicolumn{3}{|c|}{ Control (no iron) } & \multirow{2}{*}{$\begin{array}{c}\text { Risk Ratio } \\
\text { M-H, Random, } 95 \% \mathrm{Cl}\end{array}$} & \multirow{2}{*}{\multicolumn{3}{|c|}{$\begin{array}{c}\text { Risk Ratio } \\
\text { M-H, Random, } 95 \% \mathrm{Cl}\end{array}$}} \\
\hline & Events & Total & Events & Total & Weight & & & & \\
\hline \multicolumn{10}{|c|}{ 1.1.1 Developing countries } \\
\hline Batu 1976 & 17 & 36 & 29 & 34 & $12.7 \%$ & $0.55[0.38,0.80]$ & $T$ & & \\
\hline Preziosi 1997 & 41 & 99 & 69 & 98 & $13.3 \%$ & $0.59[0.45,0.77]$ & $\mathbf{T}$ & & \\
\hline Subtotal $(95 \% \mathrm{Cl})$ & & 135 & & 132 & $26.0 \%$ & $0.58[0.46,0.72]$ & $\checkmark$ & & \\
\hline Total events & 58 & & 98 & & & & & & \\
\hline \multicolumn{10}{|c|}{ Heterogeneity: $\operatorname{Tau}^{2}=0.00 ; \mathrm{Chi}^{2}=0.07, \mathrm{df}=1(\mathrm{P}=0.79) ;\left.\right|^{2}=0 \%$} \\
\hline \multicolumn{10}{|c|}{ Test for overall effect: $Z=4.98(P<0.00001)$} \\
\hline \multicolumn{10}{|c|}{ 1.1.2 Developed countries } \\
\hline Chanarin 1971 & 1 & 49 & 9 & 46 & $3.7 \%$ & $0.10[0.01,0.79]$ & & & \\
\hline Chisholm 1966 & 3 & 60 & 20 & 60 & $7.3 \%$ & $0.15[0.05,0.48]$ & & & \\
\hline Cogswell 2003 & 12 & 90 & 11 & 62 & $10.1 \%$ & $0.75[0.35,1.59]$ & & & \\
\hline De Benaze 1989 & 3 & 44 & 8 & 25 & $6.8 \%$ & $0.21[0.06,0.73]$ & & & \\
\hline Eskeland 1997 & 0 & 24 & 7 & 21 & $2.2 \%$ & $0.06[0.00,0.97]$ & & & \\
\hline Hemminki 1991 & 15 & 1336 & 56 & 1358 & $11.4 \%$ & $0.27[0.15,0.48]$ & & & \\
\hline Holly 1955 & 1 & 94 & 23 & 55 & $3.8 \%$ & $0.03[0.00,0.18]$ & & & \\
\hline Makrides 2003 & 14 & 200 & 30 & 193 & $11.2 \%$ & $0.45[0.25,0.82]$ & & & \\
\hline Milman 1991 & 0 & 100 & 15 & 107 & $2.2 \%$ & $0.03[0.00,0.57]$ & & & \\
\hline Pritchard 1958 & 6 & 74 & 23 & 49 & $9.5 \%$ & $0.17[0.08,0.39]$ & & & \\
\hline Puolakka 1980 & 0 & 16 & 6 & 15 & $2.2 \%$ & $0.07[0.00,1.18]$ & & & \\
\hline Romslo 1983 & 1 & 22 & 7 & 23 & $3.7 \%$ & $0.15[0.02,1.12]$ & & & \\
\hline Subtotal $(95 \% \mathrm{Cl})$ & & 2109 & & 2014 & $74.0 \%$ & $0.21[0.12,0.35]$ & & & \\
\hline Total events & 56 & & 215 & & & & & & \\
\hline \multicolumn{10}{|c|}{ Heterogeneity: Tau $^{2}=0.37 ; \mathrm{Chi}^{2}=24.69, \mathrm{df}=11(P=0.01) ;\left.\right|^{2}=55 \%$} \\
\hline \multicolumn{10}{|c|}{ Test for overall effect: $Z=5.90(P<0.00001)$} \\
\hline Total $(95 \% \mathrm{Cl})$ & & 2244 & & 2146 & $100.0 \%$ & $0.27[0.17,0.42]$ & & & \\
\hline Total events & 114 & & 313 & & & & & & \\
\hline \multicolumn{7}{|c|}{ Heterogeneity: $\operatorname{Tau}^{2}=0.38 ; \mathrm{Chi}^{2}=48.88, \mathrm{df}=13(\mathrm{P}<0.00001) ;\left.\right|^{2}=73 \%$} & $0 \cap 02$ & & 00 \\
\hline \multicolumn{6}{|c|}{ Test for overall effect: $Z=5.69(P<0.00001)$} & & vours experimental & Favours cor & \\
\hline
\end{tabular}

Figure 2 Impact of daily iron supplementation compared with no supplementation on anemia at term (hemoglobin less than 110g/L)

compared with no supplementation. We recommend this estimate for reduction in anemia at term for inclusion in the LiST model. The quality of evidence regarding this intervention had to be down-graded from 'high' to moderate due to some limitations like high loss to follow up [17] and unclear sequence generation [21] and also the fact that all the studies were not conducted in developing countries.

Our results show that there was not much difference in effect between iron alone and iron-folate combined. The effect sizes were similar for both the analyses but CIs were wider for that of iron/folate, mainly due to less number of studies in the pooled analysis. This shows that we can expect a similar biological effect when the iron is supplemented alone or in combination with folate. We did a subgroup for developing and developed countries. There were not sufficient studies from developing countries for all the analyses. An important observation to make in figure 2 is that even though there were two studies from developing countries, the results were very consistent $\left(\mathrm{I}^{2}=0 \%\right)$. Even though there are not a lot of randomized trials conducted in developing countries but we can suggest that iron supplementation would be much effective in developing world by looking at biological plausibility of the intervention. The populations that are most at risk for iron deficiency and IDA are young children and women of reproductive age, especially during pregnancy. The global estimates on prevalence of anemia showed that more than half the pregnant women and young children are anemic in 


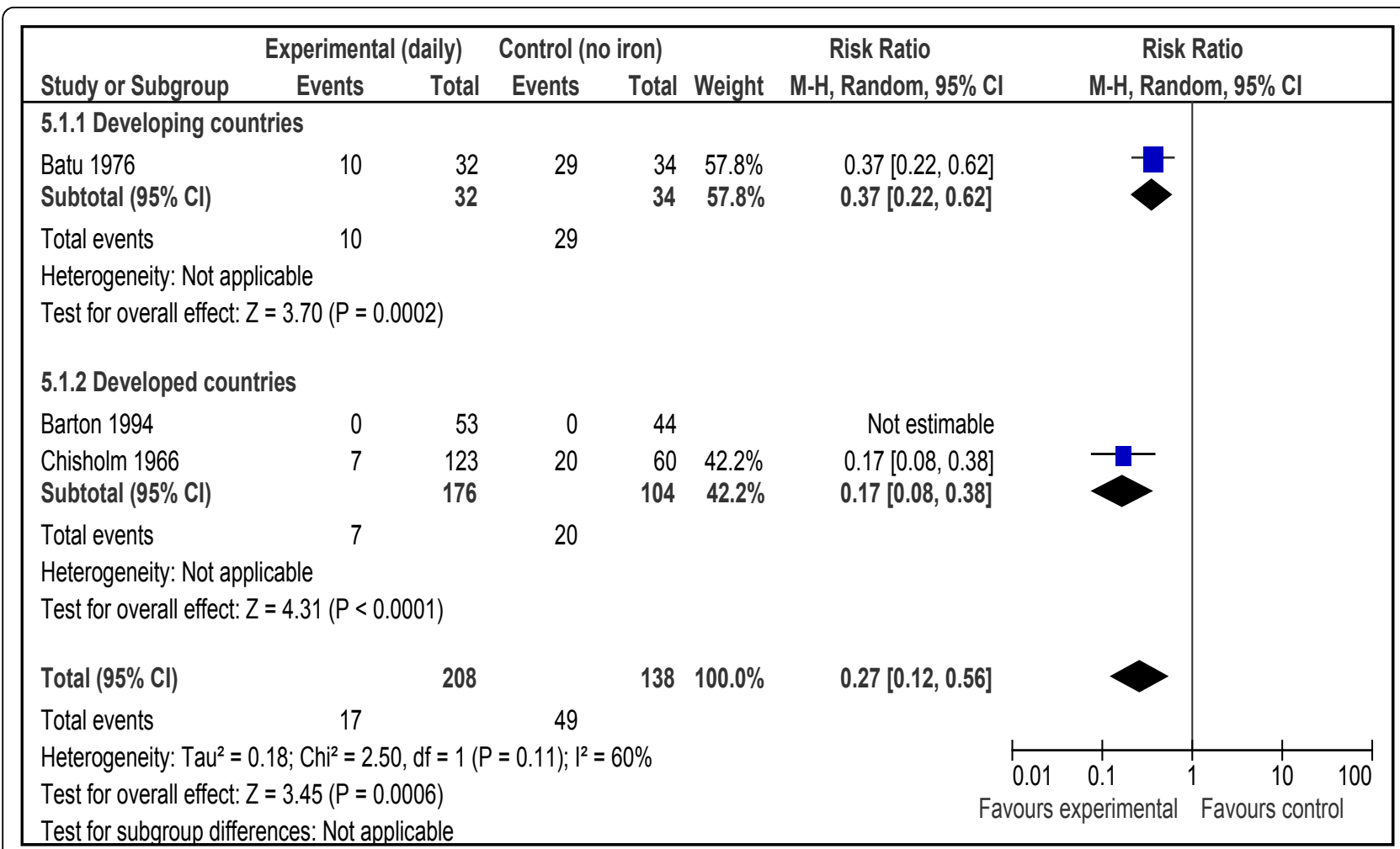

Figure 3 Impact of daily supplementation with iron and folate compared with no supplementation on anemia at term (hemoglobin less than $110 \mathrm{~g} / \mathrm{L}$ )

\begin{tabular}{|c|c|c|c|c|c|}
\hline \multirow[b]{2}{*}{ Study or Subgroup } & \multicolumn{2}{|c|}{ Experimental } & Control & Risk Ratio & \multirow{2}{*}{$\begin{array}{c}\text { Risk Ratio } \\
\text { M.H, Random, } 95 \% \mathrm{Cl}\end{array}$} \\
\hline & Events & Total & Events Total Weight & M.H, Random, $95 \% \mathrm{Cl}$ & \\
\hline Casanueva 2006 & 26 & 60 & $5 \quad 56 \quad 21.9 \%$ & $4.85[2.00,11.76]$ & $\rightarrow-$ \\
\hline Chew 1996a & 30 & 106 & $19 \quad 109 \quad 29.4 \%$ & $1.62[0.98,2.70]$ & 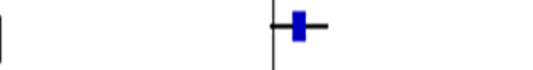 \\
\hline Chew 1996b & 8 & 46 & $6 \quad 40 \quad 20.3 \%$ & $1.16[0.44,3.06]$ & 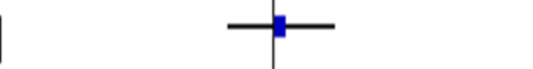 \\
\hline Liu 1996 & 13 & 56 & $32 \quad 118 \quad 28.4 \%$ & $0.86[0.49,1.50]$ & - \\
\hline Total $(95 \%$ CI) & & 268 & $323100.0 \%$ & $1.61[0.82,3.14]$ & \\
\hline Total events & 77 & & 62 & & \\
\hline $\begin{array}{l}\text { Heterogeneity: Talu } \\
\text { Test for overall effect }\end{array}$ & $\begin{array}{l}0.33 ; \mathrm{Chi} \\
z=1.390\end{array}$ & $\begin{array}{l}=11.1 \\
=0.17\end{array}$ & $d f=\left.3(P=0.01)_{1}\right|^{2}=739$ & & $\begin{array}{|lllll|}0.01 & 0.1 & 1 & 10 & 100 \\
\text { Favours experimental Favours control }\end{array}$ \\
\hline
\end{tabular}


Southeast Asia, West Pacific and Africa [48]. This shows that amount of effect would be substantially high in developing countries however more efficacy trials are required to determine the conduct of the intervention.

Weekly iron and folic acid supplementation (WIFS) is a relatively new phenomenon, and there is very little data at the moment comparing weekly supplementation with daily dosage. Weekly iron and folic acid supplementation, in synchrony with the turnover of mucosal cells, may be a promising substitute for daily iron supplementation and has been proposed as a more efficient preventive approach in public health programs $[49,50]$. The WHO says that WIFS should be considered a strategy for prevention of iron deficiency in population groups where the prevalence of anemia is above $20 \%$ among women of reproductive age and mass fortification programs of staple foods with iron and folic acid are unlikely to be implemented within 1-2 years. However, conclusive data regarding its efficacy as compared to the daily regimen are not yet available. Weekly dosage may have benefits of reduced side effects and increased compliance, but more field randomized controlled trials are needed to establish the efficacy of weekly supplementation compared to daily regimen.

\section{Conclusions}

Iron supplementation has a significant benefit in reducing anemia and iron deficiency anemia at term. Iron in combination with folic acid also has a beneficial impact on anemia at term and should be routinely used in pregnant women at least in developing countries to reduce the incidence of anemia due to increased demands during pregnancy.

\section{Additional material}

Additional File 1: Excluded Studies and Reasons for Exclusion. This is an excel file.

\section{Acknowledgment}

This work was supported in part by a grant to the US Fund for UNICEF from the Bill \& Melinda Gates Foundation (grant 43386) to "Promote evidencebased decision making in designing maternal, neonatal and child health interventions in low- and middle-income countries".

This article has been published as part of BMC Public Health Volume 11 Supplement 3, 2011: Technical inputs, enhancements and applications of the Lives Saved Tool (LiST). The full contents of the supplement are available online at http://www.biomedcentral.com/1471-2458/11?issue=S3.

\section{Authors' contributions}

Professor Zulfiqar A Bhutta developed the parameters and scope for the review and secured support. Dr Mohammad Yawar Yakoob undertook the literature search, data extraction and wrote the manuscript along under the supervision of Professor Bhutta.
}

\section{Competing interests}

We do not have any financial or non-financial competing interests for this review.

Published: 13 April 2011

\section{References}

1. World Health Organization: Micronutrient deficiencies. [http://www.who. int/nutrition/topics/ida/en/index.html].

2. Pena-Rosas JP, Viteri FE: Effects and safety of preventive oral iron or iron +folic acid supplementation for women during pregnancy. Cochrane Database Syst Rev 2009, , 4: CD004736.

3. Worldwide prevalence of anaemia 1993-2005. WHO Global Database on Anaemia. Geneva: World Health Organization;de Benoist B, McLean E, Egli I, Cogswell M [http://whqlibdoc.who.int/publications/2008/ 9789241596657_eng.pdf].

4. World Health Organization: The World Health Report - conquering suffering, enriching humanity. Geneva, Switzerland; 1997.

5. Murphy JF, O'Riordan J, Newcombe RG, Coles EC, Pearson JF: Relation of haemoglobin levels in first and second trimesters to outcome of pregnancy. Lancet 1986, 1(8488):992-995.

6. Bothwell $\mathrm{TH}$ : Iron requirements in pregnancy and strategies to meet them. Am J Clin Nutr 2000, 72(1 Suppl):257S-264S.

7. International Nutritional Anemia Consultative Group (INACG), World Health Organization (WHO), United Nations Childrens Fund (UNICEF): Guidelines for the use of iron supplements to prevent and treat iron deficiency anaemia. Washington DC: ILSI Press; 1998.

8. Villar J, Merialdi M, Gulmezoglu AM, Abalos E, Carroli G, Kulier R, de Onis M: Nutritional interventions during pregnancy for the prevention or treatment of maternal morbidity and preterm delivery: an overview of randomized controlled trials. J Nutr 2003, 133(5 Suppl 2):16065-1625S.

9. Beaton $\mathrm{GH}$ : Iron needs during pregnancy: do we need to rethink our targets? Am J Clin Nutr 2000, 72(1 Suppl):265S-271S.

10. Walker N, Fischer-Walker C, Bryce J, Bahl R, Cousens S: Standards for CHERG reviews of intervention effects on child survival. Int J Epidemiol 2010, 39(Suppl 1):i21-31.

11. Sloan NL, Jordan E, Winikoff B: Effects of iron supplementation on maternal hematologic status in pregnancy. Am J Public Health 2002, 92(2):288-293.

12. Worlbank: WorldBank. Data - Country Classification. 2008. 2008 [http:// web.worldbank.org/].

13. Batool AH, Yakoob MY, Imdad A, Bhutta ZA: Effect of multiple micronutrient supplementation during pregnancy on maternal and birth outcomes. BMC Public Health 2010.

14. Reveiz L, Gyte GM, Cuervo LG: Treatments for iron-deficiency anaemia in pregnancy. Cochrane Database Syst Rev 2007, 2: CD003094.

15. Atkins D, Best D, Briss PA, Eccles M, Falck-Ytter Y, Flottorp S, Guyatt GH, Harbour RT, Haugh MC, Henry D, et al: Grading quality of evidence and strength of recommendations. BMJ 2004, 328(7454):1490.

16. Barton DP, Joy MT, Lappin TR, Afrasiabi M, Morel JG, O'Riordan J, Murphy JF, $\mathrm{O}$ 'Herlihy C: Maternal erythropoietin in singleton pregnancies: a randomized trial on the effect of oral hematinic supplementation. Am J Obstet Gynecol 1994, 170(3):896-901.

17. Batu AT, Toe T, Pe H, Nyunt KK: A prophylactic trial of iron and folic acid supplements in pregnant Burmese women. Isr J Med Sci 1976, 12(12):1410-1417.

18. Butler EB: Effect of iron and folic acid on red cell and plasma volume in pregnancy. J Obstet Gynaecol Br Commonw 1968, 75(5):497-510.

19. Chanarin I, Rothman D: Further observations on the relation between iron and folate status in pregnancy. Br Med J 1971, 2(5753):81-84.

20. Chew F, Torun B, Viteri FE: Comparison of weekly and daily iron supplementation to pregnant women in Guatemala (supervised and unsupervised). FASEB Journal 1996, 10:A4221.

21. Chisholm M: A controlled clinical trial of prophylactic folic acid and iron in pregnancy. Journal of Obstetrics and Gynaecology of the British Commonwealth 1966, 73:191-196.

22. Christian P, Shrestha J, LeClerq SC, Khatry SK, Jiang T, Wagner T, Katz J, West KP Jr.: Supplementation with micronutrients in addition to iron and 
folic acid does not further improve the hematologic status of pregnant women in rural Nepal. J Nutr 2003, 133(11):3492-3498.

23. Cogswell ME, Parvanta I, Ickes L, Yip R, Brittenham GM: Iron supplementation during pregnancy, anemia, and birth weight: a randomized controlled trial. Am J Clin Nutr 2003, 78(4):773-781.

24. De Benaze C, Galan P, Wainer R, Hercberg S: Prevention of iron-deficiency anemia in pregnancy using early iron supplementation: a controlled trial. Rev Epidemiol Sante Publique 1989, 37(2):109-118.

25. Ekstrom EC, Hyder SM, Chowdhury AM, Chowdhury SA, Lonnerdal B, Habicht JP, Persson LA: Efficacy and trial effectiveness of weekly and daily iron supplementation among pregnant women in rural Bangladesh: disentangling the issues. Am J Clin Nutr 2002, 76(6):1392-1400

26. Hyder SM, Persson LA, Chowdhury AM, Ekstrom EC: Do side-effects reduce compliance to iron supplementation? A study of daily- and weekly-dose regimens in pregnancy. J Health Popul Nutr 2002, 20(2):175-179.

27. Eskeland B, Malterud K, Ulvik RJ, Hunskaar S: Iron supplementation in pregnancy: is less enough? A randomized, placebo controlled trial of low dose iron supplementation with and without heme iron. Acta Obstet Gynecol Scand 1997, 76(9):822-828.

28. Harvey LJ, Dainty JR, Hollands WJ, Bull VJ, Hoogewerff JA, Foxall RJ, McAnena L, Strain JJ, Fairweather-Tait SJ: Effect of high-dose iron supplements on fractional zinc absorption and status in pregnant women. Am J Clin Nutr 2007, 85(1):131-136.

29. Hemminki E, Rimpela U: A randomized comparison of routine versus selective iron supplementation during pregnancy. J Am Coll Nutr 1991, 10(1):3-10.

30. Holly RG: Anemia in pregnancy. Obstet Gynecol 1955, 5(4):562-568.

31. Lee J, Lee JA, Lim HS: Effect of time of initiation and dose of prenatal iron and folic acid supplementation on iron and folate nutriture of Korean women during pregnancy. Am J Clin Nutr 2005, 82(4):843-849.

32. Liu XN, Liu PY: The effectiveness of weekly iron supplementation regimen in improving the iron status of Chinese children and pregnant women. Biomed Environ Sci 1996, 9(2-3):341-347.

33. Makrides M, Crowther CA, Gibson RA, Gibson RS, Skeaff CM: Efficacy and tolerability of low-dose iron supplements during pregnancy: a randomized controlled trial. Am J Clin Nutr 2003, 78(1):145-153.

34. Milman $\mathrm{N}$, Agger $\mathrm{AO}$, Nielsen OJ: Iron supplementation during pregnancy. Effect on iron status markers, serum erythropoietin and human placental lactogen. A placebo controlled study in 207 Danish women. Dan Med Bull 1991, 38(6):471-476.

35. Mukhopadhyay A, Bhatla N, Kriplani A, Pandey RM, Saxena R: Daily versus intermittent iron supplementation in pregnant women: hematological and pregnancy outcome. J Obstet Gynaecol Res 2004, 30(6):409-417.

36. Pita Martin de Portela ML, Langini SH, Fleischman S, Garcia M, Lopez LB, Guntin R, Ortega Soler CR: Effect of iron supplementation and its frequency during pregnancy. Medicina (B Aires) 1999, 59(5 Pt 1):430-436.

37. Preziosi P, Prual A, Galan P, Daouda H, Boureima H, Hercberg S: Effect of iron supplementation on the iron status of pregnant women: consequences for newborns. Am J Clin Nutr 1997, 66(5):1178-1182.

38. Pritchard JA, Hunt CF: A comparison of the hematologic responses following the routine prenatal administration of intramuscular and oral iron. Surg Gynecol Obstet 1958, 106(5):516-518.

39. Puolakka J: Serum ferritin as a measure of iron stores during pregnancy. Acta Obstet Gynecol Scand Suppl 1980, 95:1-31.

40. Ridwan E, Schultink W, Dillon D, Gross R: Effects of weekly iron supplementation on pregnant Indonesian women are similar to those of daily supplementation. Am J Clin Nutr 1996, 63(6):884-890.

41. Romslo I, Haram K, Sagen N, Augensen K: Iron requirement in normal pregnancy as assessed by serum ferritin, serum transferrin saturation and erythrocyte protoporphyrin determinations. Br J Obstet Gynaecol 1983, 90(2):101-107.

42. Robinson JS, Sopacua J, Napitapulu J: Using traditional birth attendants to improve iron tablet utilization by pregnant women. Maluku Province, Indonesia. Draft paper. Mother Care Project Project Concern International. San Diego, CA; 1999

43. Tura S, Carenza L, Baccarani M, Bagnara M, Bocci A, Bottone P, Bresadola M, Bruzzese G, Cassano F, Coccia ME, et al: Therapy and iron supplements with ferritin iron during pregnancy. Randomized prospective study of 458 cases. Recenti Prog Med 1989, 80(11):607-614.
44. Yu KH, Yoon JS: The effect of weekly iron supplementation on iron and zinc nutritional status in pregnant women. Korean Journal of Nutrition 1998, 31(8):1270-1282.

45. Ziaei S, Norrozi M, Faghihzadeh S, Jafarbegloo E: A randomised placebocontrolled trial to determine the effect of iron supplementation on pregnancy outcome in pregnant women with haemoglobin $>$ or $=13.2$ g/dl. BJOG 2007, 114(6):684-688.

46. Winichagoon P, Lertmullikaporn N, Chitcumroonchokechai C, Thamrongwarangkul T: Daily versus weekly iron supplementation to pregnant women in rural northeast Thailand. Personal communication 2003.

47. Casanueva E, Viteri FE, Mares-Galindo M, Meza-Camacho C, Loria A, Schnaas L, Valdes-Ramos R: Weekly iron as a safe alternative to daily supplementation for nonanemic pregnant women. Arch Med Res 2006 37(5):674-682.

48. WHO: Global Database on anemia and iron deficiency. 1998

49. Viteri FE: A new concept in the control of iron deficiency: communitybased preventive supplementation of at-risk groups by the weekly intake of iron supplements. Biomed Environ Sci 1998, 11(1):46-60.

50. Viteri FE, Liu X, Tolomei K, Martin A: True absorption and retention of supplemental iron is more efficient when iron is administered every three days rather than daily to iron-normal and iron-deficient rats. J Nutr 1995, 125(1):82-91.

51. Agarwal KN, Agarwal DK, Mishra KP: Impact of anaemia prophylaxis in pregnancy on maternal haemoglobin, serum ferritin \& birth weight. Indian J Med Res 1991, 94:277-280.

52. Bencaiova G, von Mandach U, Zimmermann R: Iron prophylaxis in pregnancy: intravenous route versus oral route. Eur J Obstet Gynecol Reprod Biol 2009, 144(2):135-139.

53. Chan KK, Chan BC, Lam KF, Tam S, Lao TT: Iron supplement in pregnancy and development of gestational diabetes-a randomised placebocontrolled trial. BJOG 2009, 116(6):789-797, discussion 797-788.

54. Charoenlarp P, Dhanamitta S, Kaewvichit R, Silprasert A, Suwanaradd C, NaNakorn S, Prawatmuang P, Vatanavicharn S, Nutcharas U, Pootrakul P, et al: A WHO collaborative study on iron supplementation in Burma and in Thailand. Am J Clin Nutr 1988, 47(2):280-297.

55. Dommisse J, Bell DJ, Du Toit ED, Midgley V, Cohen M: Iron-storage deficiency and iron supplementation in pregnancy. S Afr Med J 1983, 64(27):1047-1051.

56. Ekstrom EC, Kavishe FP, Habicht JP, Frongillo EA Jr., Rasmussen KM, Hemed $L$ : Adherence to iron supplementation during pregnancy in Tanzania: determinants and hematologic consequences. Am J Clin Nutr 1996, 64(3):368-374.

57. Fleming AF, Ghatoura GB, Harrison KA, Briggs ND, Dunn DT: The prevention of anaemia in pregnancy in primigravidae in the guinea savanna of Nigeria. Ann Trop Med Parasitol 1986, 80(2):211-233.

58. Fleming AF, Martin JD, Hahnel R, Westlake AJ: Effects of iron and folic acid antenatal supplements on maternal haematology and fetal wellbeing. Med J Aust 1974, 2(12):429-436.

59. Gomber S, Agarwal KN, Mahajan C, Agarwal N: Impact of daily versus weekly hematinic supplementation on anemia in pregnant women Indian Pediatr 2002, 39(4):339-346.

60. Goonewardene M, Liyanage C, Fernando R: Intermittent oral iron supplementation during pregnancy. Ceylon Med J 2001, 46(4):132-135.

61. Graham JM, Haskell MJ, Pandey P, Shrestha RK, Brown KH, Allen LH: Supplementation with iron and riboflavin enhances dark adaptation response to vitamin A-fortified rice in iron-deficient, pregnant, nightblind Nepali women. Am J Clin Nutr 2007, 85(5):1375-1384

62. Guldholt IS, Trolle BG, Hvidman LE: Iron supplementation during pregnancy. Acta Obstet Gynecol Scand 1991, 70(1):9-12.

63. Hartman-Craven B, Christofides A, O'Connor DL, Zlotkin S: Relative bioavailability of iron and folic acid from a new powdered supplement compared to a traditional tablet in pregnant women. BMC Pregnancy Childbirth 2009, 9:33.

64. Khambalia AZ, O'Connor DL, Macarthur C, Dupuis A, Zlotkin SH: Periconceptional iron supplementation does not reduce anemia or improve iron status among pregnant women in rural Bangladesh. Am J Clin Nutr 2009, 90(5):1295-1302

65. Menendez C, Todd J, Alonso PL, Francis N, Lulat S, Ceesay S, M'Boge B, Greenwood BM: The effects of iron supplementation during pregnancy, 
given by traditional birth attendants, on the prevalence of anaemia and malaria. Trans R Soc Trop Med Hyg 1994, 88(5):590-593.

66. Milman N, Bergholt T, Eriksen L, Byg KE, Graudal N, Pedersen P, Hertz J: Iron prophylaxis during pregnancy - how much iron is needed? A randomized dose- response study of $20-80 \mathrm{mg}$ ferrous iron daily in pregnant women. Acta Obstet Gynecol Scand 2005, 84(3):238-247.

67. Murray-Kolb LE, Beard JL: Iron deficiency and child and maternal health. Am J Clin Nutr 2009, 89(3):946S-950S.

68. Palgi A, Levi S, Reshef A: Anemia of pregnancy: evaluation of the effectiveness of routine dietary supplementation program in an Israeli community. Am J Public Health 1981, 71(7):736-739.

69. Powers HJ, Bates CJ, Lamb WH: Haematological response to supplements of iron and riboflavin to pregnant and lactating women in rural Gambia. Hum Nutr Clin Nutr 1985, 39(2):117-129.

70. Seck BC, Jackson RT: Providing iron/folic acid tablets free of charge improves compliance in pregnant women in Senegal. Trans $R$ Soc Trop Med Hyg 2009, 103(5):485-492.

71. Seck BC, Jackson RT: Determinants of compliance with iron supplementation among pregnant women in Senegal. Public Health Nutr 2008, 11(6):596-605.

72. Siega-Riz AM, Hartzema AG, Turnbull C, Thorp J, McDonald T, Cogswell ME: The effects of prophylactic iron given in prenatal supplements on iron status and birth outcomes: a randomized controlled trial. Am J Obstet Gynecol 2006, 194(2):512-519.

73. Sood SK, Ramachandran K, Mathur M, Gupta K, Ramalingaswamy V, Swarnabai C, Ponniah J, Mathan VI, Baker SJ: W.H.O. sponsored collaborative studies on nutritional anaemia in India. 1. The effects of supplemental oral iron administration to pregnant women. Q J Med 1975, 44(174):241-258.

74. Szajewska H, Ruszczynski M, Chmielewska A: Effects of iron supplementation in nonanemic pregnant women, infants, and young children on the mental performance and psychomotor development of children: a systematic review of randomized controlled trials. Am J Clin Nutr 91(6):1690-1684.

75. Thane $T$, Thein $T$ : The effects of oral iron supplementation on ferritin levels in pregnant Burmese women. Am J Clin Nutr 1982, 35(1):95-99.

76. Wallenburg $\mathrm{HC}$, van Eijk HG: Effect of oral iron supplementation during pregnancy on maternal and fetal iron status. J Perinat Med 1984, 12(1):7-12.

77. Wu Y, Weng $L$, Wu L: Clinical experience with iron supplementation in pregnancy. Zhonghua Fu Chan Ke Za Zhi 1998, 33(4):206-208.

doi:10.1186/1471-2458-11-S3-S21

Cite this article as: Yakoob and Bhutta: Effect of routine iron supplementation with or without folic acid on anemia during pregnancy. BMC Public Health 2011 11(Suppl 3):S21.

\section{Submit your next manuscript to BioMed Central and take full advantage of:}

- Convenient online submission

- Thorough peer review

- No space constraints or color figure charges

- Immediate publication on acceptance

- Inclusion in PubMed, CAS, Scopus and Google Scholar

- Research which is freely available for redistribution

Submit your manuscript at www.biomedcentral.com/submit
Ciomed Central 